\title{
A study of multisubstituted chain transfer agents on the kinetics of homopolymerisation of methylmethacrylate .
}

\author{
Dhari -M- Abdullah
}

Chem.. depart. - college of science

Anbar university - Iraq

الخلاصة

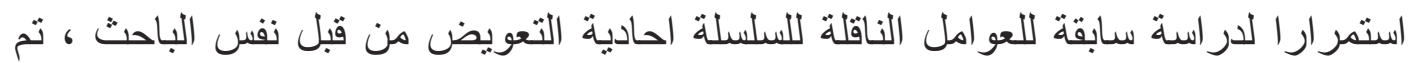

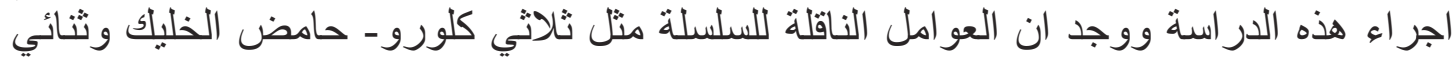

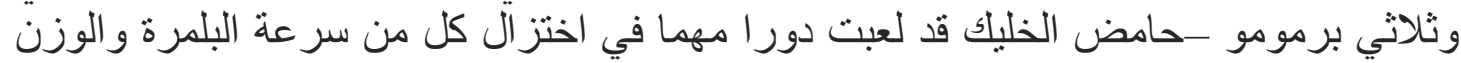

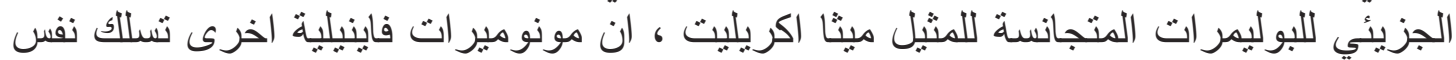

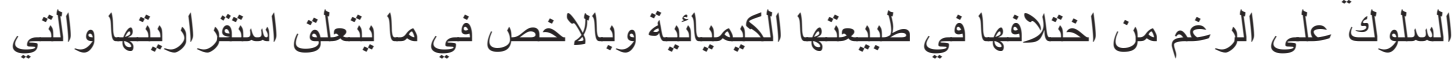

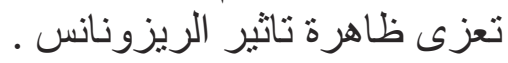
كلمات مفتاحية : مونومير اتل كبيرة , الجذور الحرة .

\section{ABSTRACT :}

A continuation to a previous study of monosubstiuted transfer agents, carried out by the same author, this investigation had been done. It has been found that multisubstituted chain transfer agents, such as tricholoro acetic acid, Di and Tribromo acetic acid, have played a significant role in the reduction of both the rate of polymerization and the molecular weights obtained of the homopolymers of methylmethacrylate, other vinylic monomers such as styrene, showed the same behavior, though they differ in their chemical nature especially that involved their stability due to the resonance effect .

Key word : Free radical-macromers

\section{INTRODUCTION}

2-Mercapto thyroxinthone (TX-SH) as a chain transfer agent $\{\mathrm{CTA}\}$ was used in the homopolymerisation of both methylmethacrylate $\{$ MMA $\}$, styrene $\quad\{$ St. $\}, \quad$ by inserting isobisazobutyronitrile $\left\{\mathrm{AIBN}\right.$ \} as initiator at $70^{\circ} \mathrm{C}$ producing a polymer holding TX groups ${ }^{(1)}$. Thioketones were used for the same purpose ${ }^{(2)}$. Though the thiols are considerably active compounds as CTA, but they have some disadvantages, such as bas smell, color and toxicity ${ }^{(3)}$. 
Trichloro acetic acid currently is used to precipitate biomacromolecules such as proteins, strictly, Deoxynucleic acid (DNA) and Ribonucleic acid (RNA) ${ }^{(4)}$. Dichloro acetic acid now a days is used as antitumor agent besides its ability as (CTA) ${ }^{(3)}$ This work aims at the investigation of some multisubstituted chain transfer agents like trichloro acetic acid (TCAA), Tri and Dichloro acetic acid (T, DBAA) over the kinetics of the homopolymerisation (MMA) .

\section{EXPERIMENTAL}

\section{A-Materials :}

1- MMA (Aldrich, 99\% purity) was distilled under vacumm $\left(33-35^{\circ} \mathrm{C}\right.$ ) and the central distillate was taken after the removal of the inhibitor by common procedures ${ }^{(5)}$.

2- Benzoyl peroxide (BP) was purified by recrystalisation from methanol. Melting point was $103{ }^{\circ} \mathrm{C}$.

3- Trichloro, Tri and Di bromo acetic acid (BDH) of purity $(98 \%, 97 \%$, 99\%) respectively were used as they are .

\section{B-polymerization :}

Serum-stopper tubes were used. Having insert the required amount of both the monomer and the initiator in the presence or absence of (CTA), the tube is stopped, and via a syringe, clean dry stream of nitrogen is let through the tube for a period of (5-10) minutes, then the tube was freed from the syringe and sealed off very well by gum, and introduced into a thermostated water bath at $\left(70 \pm 1{ }^{\circ} \mathrm{C}\right)$.

\section{RESULTS AND DISCUSSION}

Mass polymerization of MMA was carried out $\left(70 \pm 1{ }^{\circ} \mathrm{C}\right)$ using B.P as initiator at different concentrations $\left(0.6-3.3 * 10^{-2}\right) \mathrm{mol} / \mathrm{l}$, and different times (8-10) minutes, always working at conversions less than $10 \%$ to avoid the gel effect. The obtained results were tabulated in Table (1), showing reasonable accordance with that reported by Tulig and Tirrel (6) and Tobolsky ${ }^{(7)}$ et.al., bearing in mind that the polymerization follows the classic scheme and values of the constants depend on the purity of materials, in addition to the polymerization conditions. (F) was given the value 0.6 and the molecular weights were calculated by Mark-Houwink equation, using benzene as solvent at $30^{\circ} \mathrm{C}$.

Subsequently the polymerization was done in the presence of constant amount of the multisubstituted CTA, with increasing the concentrations Of the initiator till reaching a point, that the obtained molecular weights became constant, which imply that the initiator no more play a role at 
controlling the molecular weight, but the CTA only dose as shown in tables(2-3-4) the concentration of the initiator was taken $\left(2-6^{*} 10^{-2}\right) \mathrm{mol} / 1$ and raising the concentrations of CTA till a constant molecular weights were got. These indicate an optimum conditions to prepare prepolymers holding a terminal group of CTA capable of transforming to a macromer structure. The rates of polymerization were taken as $\{\%$ conv. It $(\mathrm{sec})\}$. $\{\mathrm{M}\}^{(8)}$. The CTA used were found to be of degraditive nature towards the rate of polymerization, in the following order TCAA> TBAA> DBAA as in Tables $(5,6,7)$ indicated, below showed that the multisubstituted chain transfer agent are highly active in comparison with that monosubstituted.

\section{REFERENCES:}

1.Jesus Guillermo and et.al., macromolecular Reactions Engineering $3(4), 178(2009)$.

2.Jesus Guillermo and et.al., Macromolecular Rapid communications ,29(1),80,(2008) .

3.Hao lin and et.al. Japanese of clinical oncology 11(35) 2005 .

4. Hames ,B, D, Ricwood, Gel electrophoreses of proteins ,practical Approach , $3^{\text {rd }}$ ed.IRL, 1984 press Limited, England .

5. Pyriadi ,T.M.A, practical polymer chem.. Bag.univ.1983

6.Tulig ,T, E, Tirrell, Y, M, Macromolecules 15,459(1982).

7.Ferrington ,T, E. Tobolosky A,V J.A.C.S, 77,4510(1955) .

8.Yamashita .Y.et.al.poln.J,14,255(1982) . 
Dhari -M- Abdullah

(2) 